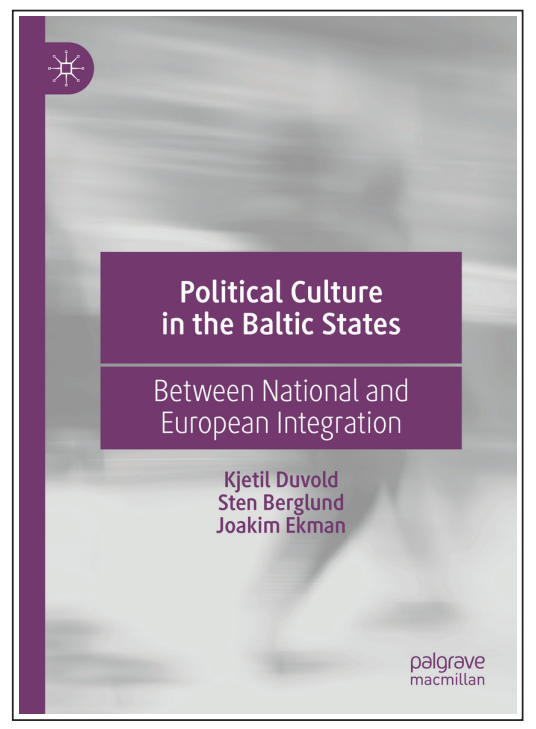

\title{
Political Culture in the Baltic States: Between National and European Integration
}

\author{
Kjetil Duvold, Sten Berglund \& Joakim Ekman \\ Cham: Palgrave Macmillan 2020 \\ 220 sidor. ISBN 9783030218430
}

Recenserad av Jonas Linde [professor, Institutt for sammenliknende politikk, Universitetet i Bergen, jonas.linde@uib.no]

I boken Political Culture in the Baltic States: Between National and European Integration anlägger Kjetil Duvold, Sten Berglund och Joakim Ekman ett komparativt perspektiv på politiska attityder bland befolkningarna i Estland, Lettland och Litauen. Det har skrivits många böcker och forskningsartiklar om den politiska utvecklingen och politiska attityder i Central- och Östeuropa (inkluderat de baltiska staterna) under de tre decennier som passerat sedan kommunismen föll och Sovjetunionen upplöstes. Det är emellertid flera saker som gör just denna studie både angelägen och aktuell.

Boken bygger på ett stort surveydatamaterial. Genom att kombinera New Baltic Barometer 1 (1993) till 6 (2004) med två nyare surveys - Baltic Barometer (2014) och Post-Crimea Barometer (2015) - insamlade inom ramen för forskningsprojektet European Values under Attack? täcker författarna mer än 20 år av politisk, ekonomisk och social omvälvning i de baltiska staterna. Huvuddelen av analyserna bygger dock på undersökningen från 2014 .

Givet författarnas tidigare forskargärning och de baltiska staternas geopolitiska läge, insprängt mellan öst och väst, är det föga överraskande att de empiriska analyserna underbyggs av ett utpräglat historiskt perspektiv och ett fokus på stats- och nationsbyggande, demokrati och integration. Den etniska dimensionen av den politiska kulturen i de baltiska staterna är en tematik som går som en röd tråd genom bokens alla kapitel. Fram träder en bild av starka skiljelinjer mellan den titulära befolkningen och den etniska minoriteten; framför allt i Estland och Lettland. Men även om skillnaderna mellan den titulära befolkningen och den ryska minoriteten 2014 fortfarande är framträdande på många områden så har stats- och 
nationsbyggnadsprocessen gått framåt. År 2004 identifierade sig två tredjedelar av den ryska minoriteten i Estland främst med Ryssland och endast två procent med den estniska staten. Motsvarande siffror tio år senare var 11 och 28 procent. I Lettland har utvecklingen varit den samma.

Den relativt positiva utvecklingen när det gäller stats- och nationsbyggande återspeglas emellertid inte när det gäller den ryska minoritetens uppfattningar om demokrati. Detta gäller både synen på ett demokratiskt styrelseskick som sådant och mer specifika utvärderingar av hur demokratin och dess institutioner fungerar i praktiken. Detta illustreras på ett utförligt sätt genom hela boken och sammanfattas på ett tydligt sätt i slutkapitlet, där författarna konstruerar en typologi baserad på två variabler; hur (miss)nöjd man är med hur det demokratiska systemet fungerar i praktiken och vilken tidsperiod man upplever har varit bäst för landet (efter/före självständigheten). Det mönster som framträder uppvisar slående skillnader, både inom och mellan de tre länderna. Det är bara majoritetsbefolkningen i Estland som är generellt sett nöjda med hur demokratin fungerar och samtidigt håller den postkommunistiska eran högst. På motsatt sida finner vi den ryska minoriteten i Lettland som uppvisar ett generellt missnöje med dagens demokrati och värderar tiden innan Lettlands självständighet högre än nutiden. Däremellan återfinns majoritetsbefolkningen i Lettland och Litauen. De ryska minoriteterna i Estland och Litauen uppvisar samma mönster som i Lettland, men är i genomsnitt lite mindre missnöjda och nostalgiska än i Lettland.

Sammantaget så visar det gedigna datamaterialet på ett tydligt sätt att Estland har lyckats bäst när det gäller konsolideringen av ett liberalt demokratiskt system och en gynnsam demokratisk politisk kultur, medan utmaningarna har visat sig vara större i Lettland och Litauen. Detta är förstås inte på något sätt överraskande för den som på avstånd följt den politiska utvecklingen i det postkommunistiska Centraloch Östeuropa. Denna bok har emellertid mycket att bjuda på när det gäller att förstå de bakomliggande orsakerna till den observerade variationen både mellan och inom de tre länderna. Det historiska perspektivet förser mer oinvigda läsare med en grundläggande förståelse av förutsättningarna för demokratins status i dessa tre relativt unga demokratier i ett utsatt geopolitiskt läge mellan etablerade demokratier i väst och ett alltmer auktoritärt och aggressivt Ryssland i öst. De specialdesignade surveyundersökningarna - tillsammans med de äldre New Baltic Barometer - ger författarna väldigt goda förutsättningar att gå på djupet och analysera stats- och nationsbyggande, demokrati och integration med hjälp av en ovanligt bred uppsättning indikatorer.

Samtidigt kan det rikliga datamaterialet för läsaren ibland framstå som något överväldigande. Över bokens drygt 200 sidor presenteras inte mindre än 62 tabeller och 13 figurer. Den empiriska analysen är nästan uteslutande av mer deskriptiv karaktär och presenterar procentfördelningar sorterade på länder och majoritetsoch minoritetsbefolkning. Bara vid ett tillfälle går analysen lite mer på djupet i form av en multivariat regressionsanalys. Med det imponerande datamaterialet författarna 
har tillgång till framstår det som förvånande att de inte på ett mer systematiskt sätt undersöker betydelsen av etnisk tillhörighet när det gäller exempelvis stöd för demokrati och alternativa styrelseskick eller tillfredsställelse med demokratins funktionssätt. En annan sak som saknas är ett bredare komparativt anslag som relaterar förhållandena i de tre länderna till andra länder, både i Öst- och Västeuropa. Flera av de indikatorer som avhandlas finns också tillgängliga $i$ andra flernationella surveys och kunde enkelt ha utgjort underlag för intressanta jämförelser. Ett bredare jämförande perspektiv skulle ge läsaren en mer nyanserad bild av den politiska kulturen $\mathrm{i}$ de baltiska staterna och man skulle inte behöva fundera över om det faktum att 41 procent av de etniska letterna säger sig vara nöjda med hur demokratin fungerar bör betraktas som problematiskt eller helt normalt i en relativt ny demokrati.

Sammanfattningsvis kan dock konstateras att Political Culture in the Baltic States: Between National and European Integration är en välskriven och läsvärd bok med mycket att erbjuda både för den initierade områdesspecialisten och för läsaren med ett mer allmänt intresse för demokrati och politisk kultur. 